\title{
Modulatory role of creatine in Parkinson's disease
}

\author{
Shaimaa A. ElShebiney ${ }^{1}$, Dalia Abuelfadl ${ }^{2}$ and Omar M. Abdel-Salam ${ }^{1}$
}

${ }^{I}$ Department of Toxicology and Narcotics, National Research Centre (NRC), 33 El-Buhouth St., 12622 Dokki, Giza, Egypt.

${ }^{2}$ Department of Pathology, National Research Centre (NRC), 33 El-Buhouth St., 12622 Dokki, Giza, Egypt.

Received: 28 Oct. 2019 / Accepted 30 Dec. 2019 / Publication date: 15 Jan. 2020

\begin{abstract}
Creatine is considered a rich dietary supplement that has beneficial antioxidant and neuroprotective role. Its use with Parkinson's disease (PD) is not well verified and needs further investigations. The current study evaluated this supplement in a mouse model of PD respecting motor effects, biochemical changes and pathophysiological modulation. Rotenone $(1.5 \mathrm{mg} / \mathrm{kg}$, s.c., day after day for two weeks) was used to induce PD in adult male Swiss mice. Creatine monohydrate was given in two doses ( 370 and $720 \mathrm{mg} / \mathrm{kg}$, p.o., daily) for 21 days. L-dopa ( $25 \mathrm{mg} / \mathrm{kg}$, p.o., 21 days) was administered in combination with creatine $(370 \mathrm{mg} / \mathrm{kg}$, p.o., daily) to a separate group.

The study showed that creatine did not enhance the motor functions but improved the oxidative state and reduced the protein oxidation of striatum. In addition, Striatum paraoxonase and cholinergic activities were restored to normal rate after creatine administration. Creatine also proved added value to conventional L-dopa therapy. In conclusion, creatine dietary supplementation is of ameliorating role to pathophysiological changes associated to PD though motor functions may not be enhanced.
\end{abstract}

Keywords: Cholinesterase, Creatine monohydrate, Oxidative stress, Paraoxonase, Parkinson's disease, Striatum

\section{Introduction}

Nutritional supplements are often used in combination with pharmacological therapies to aid in relief of chronic diseases and prevention of neurodegenerative diseases, especially for elderly (Mostafavi and Hosseini, 2015). Creatine is popularly used in sports as an accepted safe and useful ergogenic aid (Kreider et al., 2017). It is naturally present in the human body (N-[aminoiminomethy]$\mathrm{N}$-methyl glycine) endogenously synthesized from aminoacids and found in the liver, kidney, pancreas, and brain (Buford et al., 2007). Creatine is also provided through diets containing fresh meat or fish. It functions in energy buffer system, which is responsible for connecting the energy production mitochondrial sites with cytosolic energy consumption sites in high energy demand tissues (Brustovetsky and Dubinsky, 2000). Moreover, creatine functions in the antioxidant mechanisms of the body (Andres et al., 2008). Oral supplementation can increase its levels to the saturated level needed for tissue and excess amount is excreted without any side injurious effects (Adhihetty and Beal, 2008). Besides its role in energy homeostasis, creatine antioxidant action involves preventing the opening of the mitochondrial permeability transition pore (Wallimann et al., 2011).

Brain creatine level in humans was reported to increase in response to mental training (Valenzuela et al., 2003). Creatine supplementation improved brain functions in young and elderly people (Rawson and Venezia, 2011), attenuated stress-induced cognitive impairment and reduced mental fatigue (Adhihetty and Beal, 2008). Indeed, it was shown to be neuroprotective in traumatic brain injury model in rats (Wyss and Schulze, 2002; Saraiva et al., 2012; Ainsley Dean et al., 2017). Parkinson's disease (PD) as an example of neurodegenerative disease is mainly of unknown etiology with mitochondrial dysfunction and oxidative stress underlying its pathophysiological processes (Betarbet et al., 2000). Rotenone, the mitochondrial complex I inhibitor, is capable of producing same PD features and resemble the human pathophysiology (Tanner et al., 2011). Rotenone induces dopaminergic cell loss and oxidative stress mediated neurotoxicty (Henchcliffe and Beal, 2008).

Corresponding Author: Shaimaa A. ElShebiney, 1Department of Toxicology and Narcotics, National Research Centre (NRC), 33 El-Buhouth St., 12622 Dokki, Giza, Egypt.

E-mail:shaimaaelshebiney@gmail.com. 
Previous studies reported the beneficial role of creatine in PD either in experimental model of MPTP or in a controlled clinical trial. However, in 2013 the clinical trial was terminated due to unsatisfactory results (Kieburtz et al., 2015) and a meta-analysis of five clinical trials showed that creatine has no observed clinical benefit in PD patients (Mo et al., 2017). Neuroprotection provided by creatine supplementation to PD rodent model is assessed in this study.

\section{Materials and Methods}

\section{Drugs}

Rotenone was obtained from Sigma-Aldrich, USA (cat\#110M114V). Creatine monohydrate was purchased from Pan Pharmaceuticals, Australia.

\section{Animals}

Adult male Swiss mice (23-26 g) were obtained from the NRC animal house (Cairo, Egypt). Mice were kept for one week to accommodate at average room temperature $\left(24 \pm 2^{\circ} \mathrm{C}\right)$ and humidity. Mice were housed in plastic cages and food and water were provided ad libitum. All work was approved by the National Research Centre Ethical Committee.

\section{Experimental design}

Mice were allocated into 5 groups ( $\mathrm{n}=10$ per group). Group 1 was kept as vehicle control group which received $(0.3 \mathrm{ml}$ of saline, p.o. and $0.1 \mathrm{ml}$ of DMSO, s.c. $)$, groups $2,3,4 \& 5$ received rotenone $(1.5 \mathrm{mg} / \mathrm{kg}$, s.c., day after day for two weeks). Groups 3 (RC 370) and 4 (RC 720) were administered creatine monohydrate ( 370 and $720 \mathrm{mg} / \mathrm{kg}$, p.o., daily for 21 days). Group 5 (RC 370+ L-dopa) was administered L-dopa $(25 \mathrm{mg} / \mathrm{kg}$, p.o., daily for 21 days) together with creatine supplement $(370$ $\mathrm{mg} / \mathrm{kg}$, p.o., daily for 21 days). Behavioral measurement was done once at the end of the study. Ldopa was used as an ensuring reference treatment in a separate group $(\mathrm{n}=4)$ and got only behavioral testing.

Twenty-four hours after the last treatment, mice were sacrificed and brains were harvested. All samples were kept frozen at $-20^{\circ} \mathrm{C}$ till analysis. Four different brain samples of each group were stored in $10 \%$ formol saline for histopathological investigation.

\section{Wire hanging test}

For the examination of muscular rigidity, the mouse was suspended by its forelimbs on a metal rod $(20 \mathrm{~cm}$ length and $0.25 \mathrm{~cm}$ in diameter) located approximately $20 \mathrm{~cm}$ above the surface. Three trials for each animal were performed.The average time the animal remains on the rod (maximum 1 min) was registered (Sanberg et al., 1996). Measurement was done before and after start of treatments.

\section{Homogenization of brain samples}

Tissues were homogenized in phosphate buffer saline, $\mathrm{pH}$ 7.4, and debris was removed by centrifugation. Supernatant was aspirated and protein content was measured using commercial kit supplied by Biolab, Egypt.

\section{Assessment of oxidative markers}

The content of reduced glutathione (GSH) was determined according to the method of (Beutler, 1963 ) using Ellman's reagent and the color produced is read spectrophotometrically at $412 \mathrm{~nm}$. Lipid peroxides expressed as malondialdehyde equivalent (MDA) were colorimetrically assayed at $532 \mathrm{~nm}$ as described by (Uchiyama and Mihara, 1978). Mitochondrial oxidative impairments were assessed in terms of nitric oxide (NO) levels. Nitric oxide (NO) was determined using Griess reagent, the absorbance was read at $540 \mathrm{~nm}$ (Guevara et al., 1998).

\section{Determination of paroxonase activity (PON1)}

The spectrophotometrical method of (Gan et al., 1991) was used for the determination of PON1 activity, which is a marker of oxidative reactions. The enzyme promotes cleavage of phenyl acetate into phenol then measured at $270 \mathrm{~nm}$ every minute over three minutes 


\section{Assay for protein carbonyl content}

The protein carbonyl content in brain was measured using 2,4-dinitrophenylhydrazine (DNPH) as described by (Levine et al., 1990). Briefly, DNPH in $2.5 \mathrm{M} \mathrm{HCl}$ was added to the brain homogenate and incubated at room temperature for $1 \mathrm{~h}$. Then, protein was precipitated, washed and redissolved in $6 \mathrm{M}$ guanidine $\mathrm{HCl}$. Absorbance was measured at $370 \mathrm{~nm}$. Carbonyl content was calculated using a molar absorption coefficient of $22,000 \mathrm{M}^{-1} \mathrm{~cm}^{-1}$.

\section{Cholinesterase activity}

Cholinergic function was measured in terms of the activities of acetylcholinesterase (AChE) and butyrylcholinesterase (BuChE) according to (Rocha et al., 1993). Briefly, 5,5-dithiobis 2-nitrobenzoic acid (DTNB,10 mM) was allowed to react with the sample at $\mathrm{pH} 7.6$ and acetylthiocholine or butyrylthiocholine were added and the change in absorbance was monitored at $412 \mathrm{~nm}$ for $3 \mathrm{~min}$. The enzyme activities were expressed as IU $/ \mathrm{mg}$ protein.

\section{Histopathological Investigation}

Different samples of brain tissue were fixed in $10 \%$ formol saline for 24 hours. Samples were washed by tap water and then serially dehydrated with ascending grades of alcohol. Specimens were cleared in xylene and embedded in paraffin. Paraffin blocks were prepared for sectioning at $4 \mu \mathrm{m}$ by sledge microtome. The obtained tissue sections were collected on glass slides, deparaffinized, and stained by hematoxylin and eosin for histopathological examination under the electric light microscope (Bancroft and Gamble, 2008).

\section{Statistical Analysis}

Wire hanging test was analyzed by student's unpaired t-test and other parameters were analyzed by One-way ANOVA followed by Tukey's multiple comparison test of significance. $\mathrm{P}<0.05$ was set as limit of significance.

\section{Results}

\section{Wire hanging test}

Assessment of fine motor skills by wire hanging test showed that rotenone weakened the grip strength of mice by $47 \%(p<0.05)$. Creatine supplementation $(370$ and $720 \mathrm{mg} / \mathrm{kg}$ ) did not improve the rotenone-induced motor impairment and even attenuated the previously reported L-dopa ameliorating effects. L-dopa standard treatment showed normal hanging time $(25.54 \pm 2.0 \mathrm{sec})$. All treated animals had significantly weaker grip strength than normal control animals $(p<0.05)$ Table (1).

Table 1: Effect of creatine supplementation on rotenone-induced motor impairment

\begin{tabular}{lc}
\hline Group & Grip strength (sec) \\
\hline Normal control & $22.43 \pm 2.13$ \\
Rotenone & $10.64 \pm 0.50^{*}$ \\
RC370 & $10.66 \pm 2.34^{*}$ \\
RC720 & $14.19 \pm 1.04^{*}$ \\
RC370+l-dopa & $11.25 \pm 2.79^{*}$ \\
\hline
\end{tabular}

Mice were administered rotenone (1.5 mg/kg, s.c., 6 doses). Creatine supplement was given (370 and $720 \mathrm{mg} / \mathrm{kg}$, p.o., 21 days) to groups RC370 and RC 720 . L-dopa ( $25 \mathrm{mg} / \mathrm{kg}$, p.o., 21 days) therapy was given in combination with creatine $370 \mathrm{mg} / \mathrm{kg}$. Student's t-test was used. * denotes significance at $\mathrm{p}<0.05$ comapred to control group.

\section{Assessment of oxidative parameters}

Rotenone caused GSH depletion in brain of mice $(1.04 \pm 0.07 \mathrm{mmol} / \mathrm{mg}$ protein, $p<0.05)$ compared to normal control animals $(1.45 \pm 0.025 \mathrm{mmol} / \mathrm{mg}$ protein). Creatine treatment at the two doses $(370$ and $720 \mathrm{mg} / \mathrm{kg})$ had an ameliorating effect $(1.23 \pm 0.029$ and $1.22 \pm 0.023 \mathrm{mmol} / \mathrm{mg}$ protein). Moreover, L-dopa administration in conjunction with creatine $(370 \mathrm{mg} / \mathrm{kg})$ increased the GSH content markedly than rotenone-induced level $(1.73 \pm 0.045 \mathrm{mmol} / \mathrm{mg}$ protein, $p<0.05)$ Figure (1a). 
Determination of MDA as an indicator for lipid peroxidation and toxic cellular reactions showed that creatine treatment had a protective effect in rotenone-induced PD model. Rotenone caused $37.7 \%$ elevation in brain MDA content (19.01 $\pm 0.93 v s .13 .87 \pm 0.81 \mathrm{nmol} / \mathrm{mg}$ protein). Creatine treatment of rotenone-induced PD animals lowered MDA by $13 \%$ at $370 \mathrm{mg} / \mathrm{kg}$ dose $(16.45 \pm 0.85 \mathrm{nmol} / \mathrm{mg}$ protein) and by $12 \%(17.83 \pm 1.33 \mathrm{nmol} / \mathrm{mg}$ protein) at the $720 \mathrm{mg} / \mathrm{kg}$ dose. Though the creatine lowering effect was not significant form rotenone treated animals, it was at a comparable level to control animals. Combination of creatine supplement and L-dopa therapy showed a marked reduc \pm 0.94 vs. tion in MDA level $20 \%(15.23 \pm 0.84 \mathrm{nmol} / \mathrm{mg}$ protein, $p<0.05)$ in comparison to rotenone-treated mice, Figure (1b).

Nitric oxide level was increased by rotenone $(83 \%, p<0.05)$ in comparison to control mice $(22.1 \pm 1.62 v s .12 .21 \pm 0.35 \mathrm{nmol} / \mathrm{mg}$ protein). However, creatine supplementation significantly decreased the rotenone induced elevation by $37.3 \%(13.80 \pm 1.0, p<0.05)$ at the $370 \mathrm{mg} / \mathrm{kg}$ dose and by $44.8 \%(12.27 \pm 0.67, p<0.05)$ at the $720 \mathrm{mg} / \mathrm{kg}$ dose. L-dopa and creatine therapy showed $48.8 \%$ reduction $(11.29 \pm 0.92, p<0.05)$, Figure (1c).

A
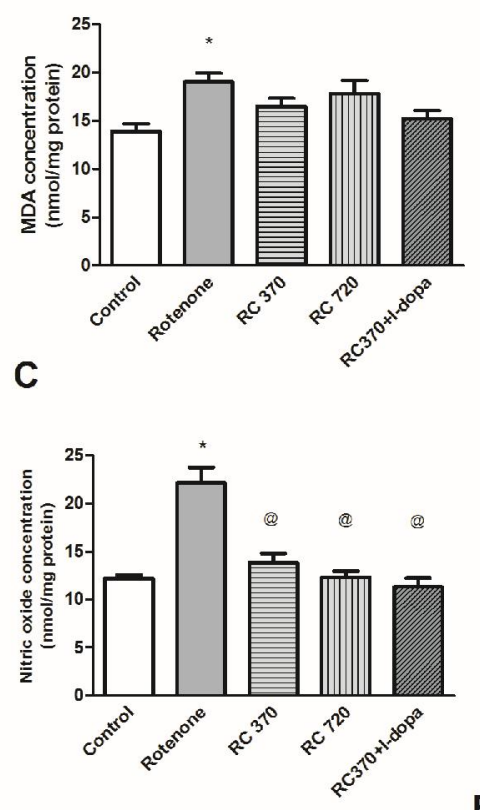

B

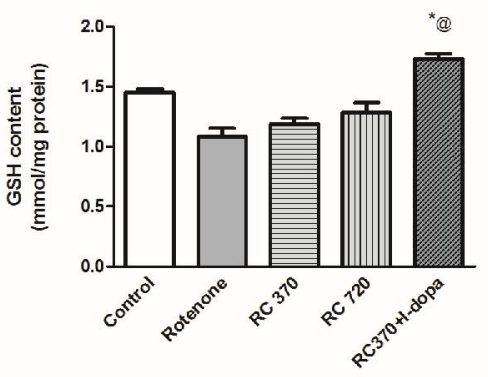

D

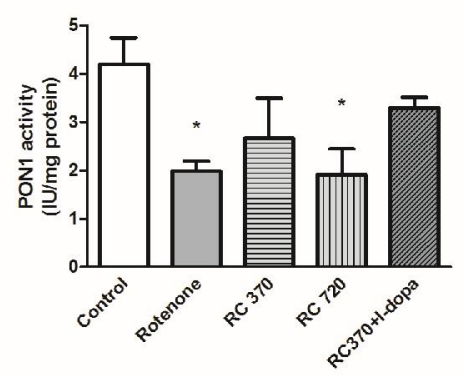

E

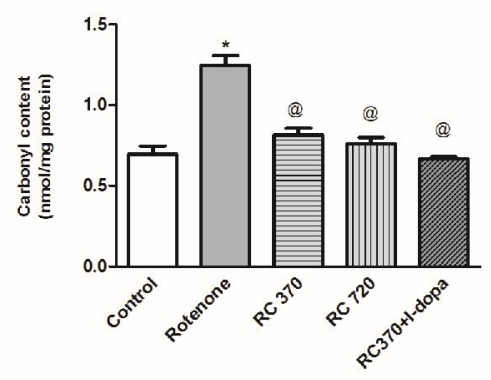

Fig. 1: Effect of creatine supplementation on oxidative state of brain; a) reducd glutathione content b) MDA content c) nitric oxide content d)PON1 activity e)Protein carbonyl content in rotenoneinduced PD in mice 
Paraoxonase activity was significantly lowered after rotenone administration compared to normal activity in control group $(1.98 \pm 0.2$ vs. $4.19 \pm 0.55 \mathrm{IU} / \mathrm{mg}$ protein, $p<0.05)$. However, creatine administration at the two dose levels did not affect that reduction $(2.67 \pm 0.82$ and $1.9 \pm 0.45 \mathrm{IU} / \mathrm{mg}$ protein, respectively). L-dopa therapy in combination with creatine supplement reversed the rotenoneinduced change in PON1 activity (3.29 $\pm 0.2 \mathrm{IU} / \mathrm{mg}$ protein), Figure (1d).

On the other side, protein oxidation products (Carbonyl content) were $0.69 \pm 0.05 \mathrm{nmol} / \mathrm{mg}$ protein in normal control animals and were increased by rotenone administration $(1.25 \pm 0.06 \mathrm{nmol} / \mathrm{mg}$ protein, $p<0.05$ ). Giving creatine supplement $(370$ and $720 \mathrm{mg} / \mathrm{kg}$ ) reduced this elevation to normal level $(0.81 \pm 0.04$ and $0.75 \pm 0.04 \mathrm{nmol} / \mathrm{mg}$ protein, $p<0.05)$. Combining the creatine supplement with L-dopa therapy had also a pronounced effect $(0.67 \pm 0.01 \mathrm{nmol} / \mathrm{mg}$ protein, $p<0.05)$, Figure (1e).

\section{Cholinergic activity}

Cholinergic function was impaired by rotenone where it increased $\mathrm{AChE}$ and $\mathrm{BuChE}$ activities in brain by $91.8 \%(0.71 \pm 0.05 v s .0 .37 \pm 0.05 \mathrm{IU} / \mathrm{mg}$ protein) and $94.7 \%(0.37 \pm 0.02 v s .0 .19 \pm 0.01 \mathrm{IU} / \mathrm{mg}$ protein), respectively $(p<0.05)$. Treatment with creatine either alone or with L-dopa restored normal activities where AChE reached $0.25 \pm 0.11,0.33 \pm 0.02$, and $0.32 \pm 0.02 \mathrm{IU} / \mathrm{mg}$ protein in the groups $\mathrm{RC} 370, \mathrm{RC} 720$ and RC370+1-dopa, respectively. BuChE activity $0.20 \pm 0.02,0.22 \pm 0.01$, and $0.195 \pm 0.01$ in the groups RC370, RC720 and RC370+1-dopa, respectively, Figure (2).

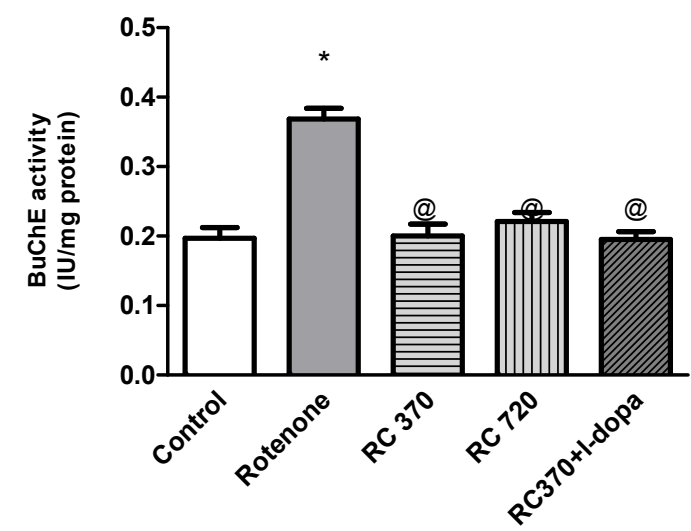

Fig. 2: Effect of creatine supplement on Acetylcholinesterase and butyryl cholinesterase activities of brain in rotenone-induced PD in mice

All mice were administered rotenone $(1.5 \mathrm{mg} / \mathrm{kg}$, s.c., day after day, 2 weeks) except control group received DMSO (s.c.) and saline (p.o.). Creatine supplement was given ( 370 and $720 \mathrm{mg} / \mathrm{kg}$, p.o., 21 days) to groups RC 370 and RC720. RC370+1-dopa was given L-dopa ( $25 \mathrm{mg} / \mathrm{kg}$, p.o., 21 days) therapy in concomitance with creatine $370 \mathrm{mg} / \mathrm{kg}$, p.o., 21 days.

* significantly different from control at $\mathrm{p}<0.05,{ }^{\circledR}$ significantly different from rotenone at $\mathrm{p}<0.05$

\section{Histopathological Investigation}

Brain histopathological examination presented the normal structure of cortical tissue and the altered degenerated tissue after rotenone administration. Pyknosis and focal apoptosis were observed in brain cortex tissue after rotenone administration. Supplementation of mice with creatine $(370$ $\mathrm{mg} / \mathrm{kg}$ ) has slightly enhanced the histological appearance of the tissue with occasional degenerated neurons and cytoplasmic vacuolations observed. However, at high creatine dose supplement (720 $\mathrm{mg} / \mathrm{kg}$ ), the brain tissue showed improved state where healthy looking neurons with focal fragmented stroma were observed and normal thickening of tissue, Figure (3). 


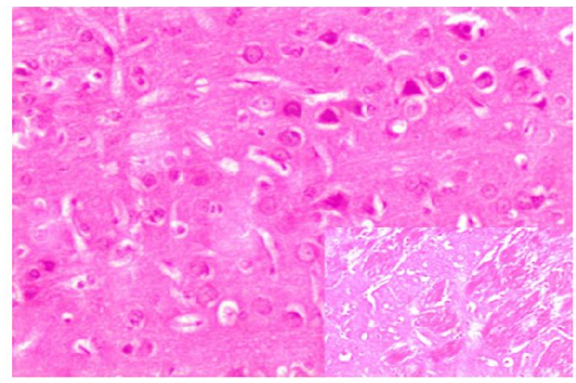

A

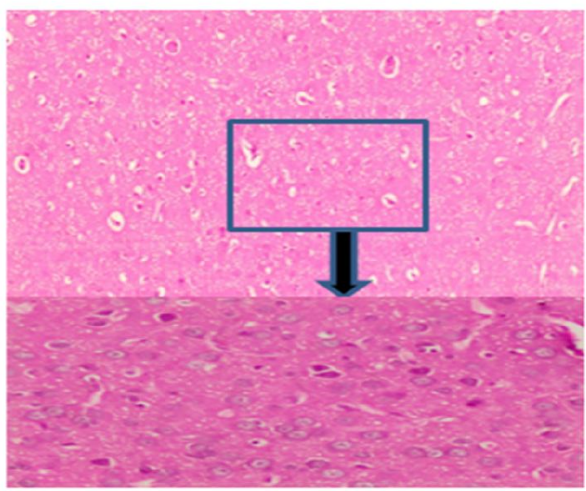

C

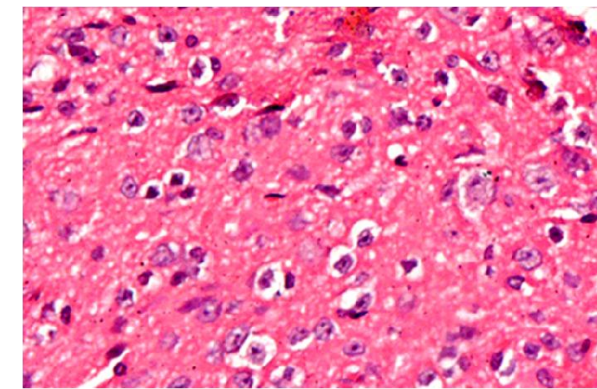

B

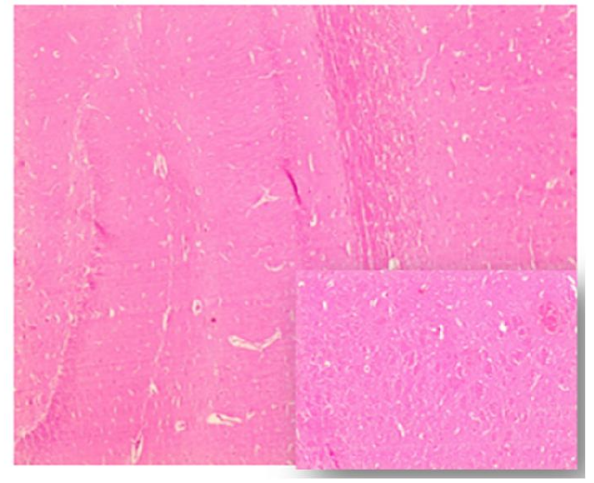

D

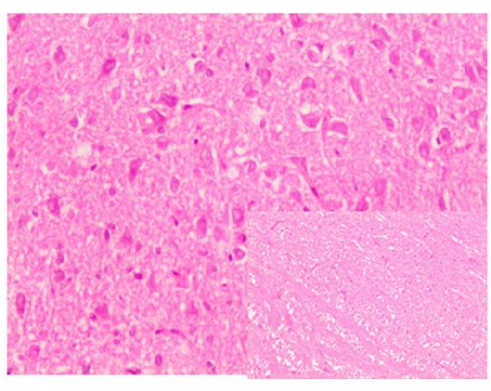

$\mathbf{E}$

Fig. 3: A) normal control showing healthy neurons and stromal edema. B) Rotenone group showing cytoplasmic vacuolations and focally apoptotic neurons C) Rotenone and creatine $(370 \mathrm{mg} / \mathrm{kg})$ showing cytoplasmic vacuolations and occasional focally degenerated neurons with intraneuronal hyaline material deposition D) Creatine $(720 \mathrm{mg} / \mathrm{kg})$ treatment showing normal neuronal layer thickness and healthy looking neurons with focal fragmented stroma $\mathbf{E}$ ) L-dopa and creatine $(370 \mathrm{mg} / \mathrm{kg}$ ) showing some enlarged neurons with slight edema (x100 and x200).

\section{Discussion}

The present study addressed the potential benefit achieved from supplementing PD animals with creatine monohydrate in the light of previous reports about its protective role in neurodegenerative disorders.

Rotenone was employed as a mitochondrial complex inhibitor in mice and it produces correspondent deleterious effects of PD in brain. Creatine supplement was given orally to mice in two doses 370 and $720 \mathrm{mg} / \mathrm{kg}$ or the $370 \mathrm{mg} / \mathrm{kg}$ dose in combination with the conventional therapy, Ldopa for three weeks. It was shown that creatine supplementation at both doses reduced the oxidative stress biomarkers in brain tissue, restored cholinergic normal activity and improved the histological appearance of brain tissue. However, motor functions did not improve with creatine supplementation alone. It is noteworthy that the lower dose effect was equivalent to the effect of the higher dose annotating that there is no dose-related effects thus the lower dose was employed in the combination with L-dopa. 
Most neurodegenerative disorders including PD are associated with oxidative stress, mitochondrial dysfunction and energy depletion (Browne and Beal, 1994; Trushina and McMurray, 2007). These underlying pathophysiological processes may be either a primary or a secondary cause of cell death and controlling these processes could have a beneficial role in progress of the disease.

Rotenone through inhibiting complex I in the mitochondrial electron transport chain produces ATP depletion and deterioration of dopaminergic neurons in substantia nigra reproducing the main feature of PD with the consequent motor dysfunction (Alam and Schmidt, 2002).

On the other hand, creatine is engaged in energy production via oxidative phosphorylation and synthesis of ATP critical to cerebral function. Several reports associated disruption of neuronal functions and occurrence of intramitochondrial inclusions with creatine depletion (Wyss and Wallimann, 1994).

Furthermore, creatine has a direct anti-apoptotic effect in CNS through preventing the early mitochondrial permeability transition pore opening (Dolder et al., 2003). Creatine supplementation was shown to directly scavenge reactive oxygen species and reduce their production from mitochondria (Meyer et al., 2006; Sestili et al., 2006). Moreover, Young et al. (2010) related the increase in antioxidant pool of GSH to up-regulation of the thiol redox system induced by creatine.

Consequently, the observed antioxidant effect in the present study can be linked directly to the mitochondrial improving effect of creatine where it attenuated the rotenone produced toxicity.

In accordance, previous studies consigned the brain protective role of creatine diet supplementation in mice and rats against traumatic brain injury to decreased free radicals, maintenance of mitochondrial membrane potential, and upholding the levels of ATP (Sullivan et al., 2000; Brustovetsky et al., 2001; Jiang et al., 2001). Other in vitro studies support these mechanisms in PD paradigm in ventral mesencephalic rat cultures (Andres et al., 2008).

Clinically, creatine supplementation in pilot studies resulted in unchanged Unified Parkinson's disease rating scale (Bender et al., 2006), though it slowed down the progression of the disease in a phase II clinical trial. Nonetheless, a randomized clinical study reported unaltered state of PD patients and suggested that it is of no value for such patients.

The study of Saraiva et al.(2012) described an anti-oxidant role for creatine in traumatic brain injury in rats depending on prevention of oxidative cascades without affecting the related behavioral deficits and seizures.

Cholinergic neurons are widely distributed throughout the CNS to regulate vital functions, such as learning, memory, cortical organization of movement and cerebral blood flow control (Dani, 2001). $\mathrm{AChE}$ is an important enzyme for cholinergic neurotransmission and plays a key role in regulating neurobehavioral processes. Overactivation of cholinergic receptors and toxic related effects such as confusion, headache, sleep and memory disturbances occur in consequence of AChE inhibition (Bombois et al., 2010).

In addition, there is an evidence for early alterations in cholinergic neurotransmission in PD and its association to motor deficits. The current study showed restored cholinergic activity in brain after creatine supplementation besides a supportive effect to the conventional dopaminergic treatment. The observed effects were further confirmed through histological evaluation where a dose-dependent marked reduction of apoptotic neurons and enhanced brain structure were described. Therefore the results of the current study emphasize the supportive role of creatine in the motor disorder and prove its antioxidant activity.

It was of added value to the commonly used therapy, L-dopa suggesting its capacity to delay the related side effects. Taken all together, creatine can be a premium dietary supplement for PD patients in limited doses and can support current therapies molecularly. Clinical studies have to elucidate these findings and report the molecular and cellular changes related to its use in therapeutic paradigm.

\section{References}

Adhihetty, P.J. and M.F. Beal, 2008. Creatine and its potential therapeutic value for targeting cellular energy impairment in neurodegenerative diseases: Neuromolecular medicine, 10 (4): 275-290.

Ainsley Dean, P.J., G. Arikan, B. Opitz, and A. Sterr, 2017. Potential for use of creatine supplementation following mild traumatic brain injury: Concussion, 2(2): CNC34, doi:10.2217/cnc-2016-0016. 
Alam, M. and W.J. Schmidt, 2002. Rotenone destroys dopaminergic neurons and induces parkinsonian symptoms in rats: Behavioural brain research, 136(1): 317-324.

Andres, R.H., A.D. Ducray, U. Schlattner, T. Wallimann, and H.R. Widmer, 2008. Functions and effects of creatine in the central nervous system: Brain Research Bulletin, 76(4):329-343, doi:10.1016/j.brainresbull.2008.02.035.

Bancroft, J.D., and M. Gamble, 2008. Theory and practice of histological techniques: Elsevier Health Sciences, 443-96 p.

Bender, A., W. Koch, M. Elstner, Y. Schombacher, J. Bender, M. Moeschl, F. Gekeler, B. MüllerMyhsok, T. Gasser, and K. Tatsch, 2006. Creatine supplementation in Parkinson disease: a placebo-controlled randomized pilot trial: Neurology, 67(7): 1262-1264.

Betarbet, R., T.B. Sherer, G. MacKenzie, M. Garcia-Osuna, A.V. Panov, and J.T. Greenamyre, 2000, Chronic systemic pesticide exposure reproduces features of Parkinson's disease: Nature Neuroscience, 3(12): 1301-1306, doi:10.1038/81834.

Beutler, E., 1963. Improved method for the determination of blood glutathione: J. lab. clin. Med., 61:882-888

Bombois, S., P. Derambure, F. Pasquier, and C. Monaca, 2010. Sleep disorders in aging and dementia: The journal of nutrition, health \& aging, 14(3):212-217.

Browne, S.E., and M.F. Beal, 1994. Oxidative damage and mitochondrial dysfunction in neurodegenerative diseases: Portland Press Limited.

Brustovetsky, N., T. Brustovetsky and J.M. Dubinsky, 2001. On the mechanisms of neuroprotection by creatine and phosphocreatine: Journal of Neurochemistry, 76(2):425-434.

Brustovetsky, N., and J.M. Dubinsky, 2000. Dual responses of CNS mitochondria to elevated calcium: The Journal of Neuroscience: The Official Journal of the Society for Neuroscience, 20(1):103-113.

Buford, T.W., R.B. Kreider, J.R. Stout, M. Greenwood, B. Campbell, M. Spano, T. Ziegenfuss, H. Lopez, J. Landis, and J. Antonio, 2007. International Society of Sports Nutrition position stand: creatine supplementation and exercise: Journal of the International Society of Sports Nutrition, 4: 6, doi:10.1186/1550-2783-4-6.

Dani, J. A., 2001. Overview of nicotinic receptors and their roles in the central nervous system: Biological Psychiatry, 49(3): 166-174, doi:10.1016/S0006-3223(00)01011-8.

Dolder, M., B. Walzel, O. Speer, U. Schlattner, and T. Wallimann, 2003. Inhibition of the mitochondrial permeability transition by creatine kinase substrates Requirement for microcompartmentation: Journal of Biological Chemistry, 278(20):17760-17766.

Gan, K.N., A. Smolen, H.W. Eckerson, and B.N. La Du, 1991. Purification of human serum paraoxonase/arylesterase. Evidence for one esterase catalyzing both activities.: Drug Metabolism and Disposition, 19(1): 100-106.

Guevara, I., J. Iwanejko, A. Dembińska-Kieć, J. Pankiewicz, A. Wanat, P. Anna, I. Gołąbek, S. Bartuś, M. Malczewska-Malec, and A. Szczudlik, 1998. Determination of nitrite/nitrate in human biological material by the simple Griess reaction: Clinica Chimica Acta, 274(2):177-188, doi:10.1016/S0009-8981(98)00060-6.

Henchcliffe, C. and M.F. Beal, 2008. Mitochondrial biology and oxidative stress in Parkinson disease pathogenesis: Nature Clinical Practice. Neurology, 4(11):600-609, doi:10.1038/ncpneuro0924.

Jiang, D., P. G. Sullivan, S. L. Sensi, O. Steward, and J. H. Weiss, 2001. Zn(2+) induces permeability transition pore opening and release of pro-apoptotic peptides from neuronal mitochondria: The Journal of Biological Chemistry, 276(50):47524-47529, doi:10.1074/jbc.M108834200.

Kieburtz, K., B.C. Tilley, J.J. Elm, D. Babcock, R. Hauser, G.W. Ross, A.H. Augustine, E. U. Augustine, M.J. Aminoff, and I.G. Bodis-Wollner, 2015. Writing Group for the NINDS Exploratory Trials in Parkinson Disease (NET-PD) Investigators. Effect of creatine monohydrate on clinical progression in patients with Parkinson disease: a randomized clinical trial: JAMA, 313(6):584-593.

Kreider, R.B., D.S. Kalman, J. Antonio, T.N. Ziegenfuss, R. Wildman, R. Collins, D.G. Candow, S. M. Kleiner, A.L. Almada, and H.L. Lopez, 2017. International Society of Sports Nutrition position stand: safety and efficacy of creatine supplementation in exercise, sport, and medicine: Journal of the International Society of Sports Nutrition, 14(1):18, doi:10.1186/s12970-017-0173$\mathrm{Z}$. 
Levine, R.L., D. Garland, C.N. Oliver, A. Amici, I. Climent, A.G. Lenz, B.W. Ahn, S. Shaltiel, and E.R. Stadtman, 1990. Determination of carbonyl content in oxidatively modified proteins, in Methods in enzymology: Elsevier, p. 464-478.

Meyer, L.E., L.B. Machado, A. P. S. Santiago, W. S. da-Silva, F. G. De Felice, O. Holub, M. F. Oliveira, and A. Galina, 2006. Mitochondrial creatine kinase activity prevents reactive oxygen species generation antioxidant role of mitochondrial kinase-dependent ADP re-cycling activity: Journal of Biological Chemistry, 281(49): 37361-37371.

Mo, J.J., L.Y. Liu, W.B. Peng, J. Rao, Z. Liu, and L.L. Cui, 2017. The effectiveness of creatine treatment for Parkinson's disease: an updated meta-analysis of randomized controlled trials: BMC Neurology, v. 17, doi:10.1186/s12883-017-0885-3.

Mostafavi, S.A., and S. Hosseini, 2015. Foods and Dietary Supplements in the Prevention and Treatment of Neurodegenerative Diseases in Older Adults, in Foods and Dietary Supplements in the Prevention and Treatment of Disease in Older Adults: Elsevier, p. 63-67.

Rawson, E.S., and A.C. Venezia, 2011. Use of creatine in the elderly and evidence for effects on cognitive function in young and old: Amino Acids, 40(5):1349-1362, doi:10.1007/s00726-0110855-9.

Rocha, J.B.T., T. Emanuelli and M.E. Pereira, 1993. Effects of early undernutrition on kinetic parameters of brain acetylcholinesterase from adult rats: Acta Neurobiol. Exp., 53:431-437.

Sanberg, P.R., R. Martinez, R.D. Shytle, and D.W. Cahill, 1996. The catalepsy test, in Motor activity and movement disorders: Springer, p. 197-211.

Saraiva, A.L.L., A.P.O. Ferreira, L.F.A. Silva, M.S. Hoffmann, F.D. Dutra, A.F. Furian, M.S. Oliveira, M.R. Fighera, and L.F.F. Royes, 2012. Creatine reduces oxidative stress markers but does not protect against seizure susceptibility after severe traumatic brain injury: Brain Research Bulletin, 87(2): 180-186, doi:10.1016/j.brainresbull.2011.10.010.

Sestili, P., C. Martinelli, G. Bravi, G. Piccoli, R. Curci, M. Battistelli, E. Falcieri, D. Agostini, A.M. Gioacchini, and V. Stocchi, 2006. Creatine supplementation affords cytoprotection in oxidatively injured cultured mammalian cells via direct antioxidant activity: Free Radical Biology and Medicine, 40(5):837-849.

Sullivan, P.G., J.D. Geiger, M.P. Mattson, and S.W. Scheff, 2000. Dietary supplement creatine protects against traumatic brain injury: Annals of neurology, 48(5):723-729.

Tanner, C.M. et al., 2011, Rotenone, Paraquat, and Parkinson's Disease: Environmental Health Perspectives, 119(6):866-872, doi:10.1289/ehp.1002839.

Trushina, E., and C.T. McMurray, 2007. Oxidative stress and mitochondrial dysfunction in neurodegenerative diseases: Neuroscience, 145(4):1233-1248.

Uchiyama, M., and M. Mihara, 1978. Determination of malonaldehyde precursor in tissues by thiobarbituric acid test: Analytical biochemistry, 86(1):271-278.

Valenzuela, M.J., M. Jones, W.W.C. Rae, S. Graham, R. Shnier, and P. Sachdev, 2003. Memory training alters hippocampal neurochemistry in healthy elderly: Neuroreport, 14(10):1333-1337.

Wallimann, T., M. Tokarska-Schlattner, and U. Schlattner, 2011. The creatine kinase system and pleiotropic effects of creatine: Amino Acids, 40(5):1271-1296, doi:10.1007/s00726-011-0877-3.

Wyss, M., and A. Schulze, 2002. Health implications of creatine: can oral creatine supplementation protect against neurological and atherosclerotic disease? Neuroscience, 112(2):243-260.

Wyss, M., and T. Wallimann, 1994. Creatine metabolism and the consequences of creatine depletion in muscle, in Cellular Bioenergetics: Role of Coupled Creatine Kinases: Springer, p. 51-66.

Young, J.F., L.B. Larsen, A. Malmendal, N.C. Nielsen, I.K. Straadt, N. Oksbjerg, and H.C. Bertram, 2010. Creatine-induced activation of antioxidative defence in myotube cultures revealed by explorative NMR-based metabonomics and proteomics: Journal of the International Society of Sports Nutrition, 7(1): 9, doi:10.1186/1550-2783-7-9. 